\title{
Influence of sampling practices on the appearance of DNA image histograms of prostate cells in FNAB samples
}

\author{
Abdelbaset Buhmeida, Teijo Kuopio and \\ Yrjö Collan * \\ Department of Pathology, University of Turku, \\ Kiinamyllynkatu 10, Turku, SF-20520, Finland \\ Received 15 October 1998 \\ Revised 8 February 1999 \\ Accepted 17 February 1999
}

biopsy analysis and morphometry with DNA cytometry from the same sample. We have now found that cell types present in the sample clearly define the appearance of the histograms. Because this seems to be an important issue, and may be important in distinguishing between advancing types of prostate cancer and more stable disease, we decided to study the question in more detail.

\section{Material and methods}

nty-one fine needle aspiration biopsies (FNAB) of prostate, diagnostically classified as definitely malignant, were studied. The Papanicolaou or H\&E stained samples were destained and then stained for DNA with the Feulgen reaction. DNA cytometry was applied after different sampling rules. The histograms varied according to the sampling rule applied. Because free cells between cell groups were easier to measure than cells in the cell groups, two sampling rules were tested in all samples: (i) cells in the cell groups were measured, and (ii) free cells between cell groups were measured. Abnormal histograms were more common after the sampling rule based on free cells, suggesting that abnormal patterns are best revealed through the free cells in these samples. The conclusions were independent of the applied histogram interpretation method.

Keywords: DNA cytometry, aneuploidy, prostate, fine needle aspiration biopsy, sampling rule, diagnostics

\section{Introduction}

The importance of DNA histograms in prostate cancer has been demonstrated [2,3,6,9-11]. DNA ploidy status in prostate cancer has been defined either with flow cytometry $[7,8,13]$ or with image cytometry [15], we have started to study image cytometry applications to be able to associate standard fine needle aspiration

*Correspondence to: Y. Collan, Department of Pathology, University of Turku, Kiinamyllynkatu 10, Turku, 52, SF-20520, Finland. Tel.: +358 21613 963; Fax: +358216337459.

\subsection{Samples}

21 FNAB samples of the prostate from the period 1989-1996, graded as definitely malignant at the diagnostic phase, were studied. The samples were randomly selected from the files of a cytology laboratory. Originally the samples were stained with Papanicolaou stain or H\&E. The microscopic interpretation was based on the study by experienced, specialised cytopathologists.

\subsection{Feulgen staining}

The samples were stained with Feulgen stain according to Gaub's method [4,14]. Before staining the samples were washed in xylene for 3-7 days to remove the cover glass and embedding medium. The xylene was removed with ethanol followed by descending (99-50\%) ethanol series. The samples were washed in $1 \%(0.28 \mathrm{M})$ hydrochloric acid in $70 \%$ ethanol until destained. The samples were washed in distilled water, followed by acid hydrolysis in $5 \mathrm{M}$ hydrochloric acid at room temperature $\left(20^{\circ} \mathrm{C}\right)$ for one hour. After washing in distilled water, samples were treated in darkness with Schiff's reagent (stain: pararosaniline) for 2 hours 45 minutes at room temperature $\left(20^{\circ} \mathrm{C}\right)$, rinsed in distilled water, treated for $3 \times 10$ minutes in fresh aque- 
ous sodium tiosulphate $(180 \mathrm{ml}$ distilled water, $10 \mathrm{ml}$ $1 \mathrm{M} \mathrm{HCl}, 10 \mathrm{ml} 10 \% \mathrm{Na}_{2} \mathrm{~S}_{2} \mathrm{O}_{5}$ ), and rinsed for $5 \mathrm{~min}$ utes. After dehydration the smears were treated with xylene and mounted, then stored in shade.

\subsection{Equipment for image analysis cytometry}

The intensity of Feulgen staining was measured using a computer-assisted image analysis cytometry system with an Olympus BH2 microscope (Olympus Optical Co., Ltd., Tokyo, Japan) utilizing ACAS software (Ahrens Cytometry Analysis System for flow and static cytometry, version 5.02, Olaf Ahrens, Labor für Meßtechnische Beratung und Entwicklung, Bargteheide/Hamburg, Germany), and equipped with electrical current stabilizer. The histograms produced by this software have a resolution of 256 channels. The video camera (Panasonic WV-CD20) had a pickup device of the CCD type with $500 \times 582(291,000)$ pixels. At the objective magnification of $60 \times$ pixel width was $0.261 \mu \mathrm{m}$, and corresponding pixel area $0.068 \mu \mathrm{m}^{2}$. The computer had a video card with $512 \times 1024$ pixels. The measurements were made with a plan objective (S-Plan 60×, numerical aperture 0.30). A stabilized power supply (Laboratory DC power supply model GPS 185, Goodwill Instrument Co., Taiwan) was used for the current supply to the microscope to keep the illumination stable. A 550-nm interference filter (IF 550, Olympus) was used to increase the contrast of the stained nuclei against the background (half value width $550 \mathrm{~nm}+15 /-45$ ). Prior to each measurement session the illumination of the microscope was adjusted according to the method of Köhler. The system was calibrated prior to each session.

\subsection{Measurements}

We started our study by testing several types of sampling strategies, and these included the following:

- Selection of epithelial cells from the cell groups;

- Selection of epithelial cells at the periphery of cell groups;

- Selection of the free epithelial cells between cell groups;

- Selection of cells from epithelial cell groups, and free epithelial cells between cell groups;

- Selection of large free epithelial cells with detectable nucleoli;

- Selection of large free epithelial cells without detectable nucleoli;

- Selection of medium sized free epithelial cells;
- Selection of small free epithelial cells.

It was our idea to test whether different sampling methods could change the histogram. After reviewing the above results we made a decision on two uniform sampling methods and tested these on the 21 definitely malignant fine needle aspiration biopsies (prostate cancer biopsies).

The two sampling rules were:

- Cells from cell groups were selected. The most atypical cell groups were looked for and cells measured from them.

- Free epithelial cells between cell groups were selected.

For several reason our approach was selective. The first phase of the study clearly showed that selection greatly affected the appearance of the histograms. Our approach was to find a method which could be best able to find abnormalities from among the prostate cells. We did not use systematic sampling for several reasons:

- FNABs contained definitely benign cells, often in large numbers. We wanted to concentrate on cell groups, which on the basis of the interpretation of an experienced cytologist were definitely malignant. This was done to avoid the risk of hiding abnormal DNA findings behind DNA patterns of numerous diploid cells. The co-operation of an experienced cytologist was considered to be of utmost importance in this study. In many cell groups only the marginal cells could be measured. In general this was due to nuclear overlap among more central cells.

- Because the preliminary study showed differences between a cell group and free epithelial cells between cell groups, we wanted to study free epithelial cells only. If there were less than 150 free epithelial cells in the sample, all of them were selected for analysis. If there were more than 150 cells, we measured a total of 150-200 free cells for the sample histogram.

The observer who had a good training in DNA cytometry sampled the slides carefully with the aim of finding 200 measurable nuclei. This number could not be found in all cases due to nuclear overlap in cell groups, or due to scarcity of free epithelial cells between cell groups. On the average 105 cells were measured from cell groups $(\mathrm{SD}=45.6, \mathrm{CV}=0.43$, range $39-200)$, and 75 cells from free cells $(S D=52.7$, $\mathrm{CV}=0.70$, range 9-200). We later noted that sam- 
ples with small amounts of cells, such as the one with 9 free cells only, landed in the uninterpretable histogram category. The small numbers of measured cells in some cases were explained simply by the fact that there were no more cells to be measured. So the representativity of this method is essentially based on the size of the sample obtained through biopsing the prostate. The epithelial cells were identified subjectively by the observer (A.B.) who did the DNA measurements. Macrophages, lymphocytes, granulocytes, and interstitial cells with oblong or fusiform nuclei were avoided. In the samples no cells showing nuclear overlaps were selected for measurements. Small lymphocytes were used as diploid controls. A glare correction $[1,5]$ was made with software of the Ahrens ACAS-programme (Bargteheide/Hamburg, Germany).

\subsection{Interpretation of histograms}

We wanted to look for various kinds of interpretation of the histograms. Aneuploidy as defined in the following classifications means DNA-based aneuploidy (DNA-aneuploidy), not aneuploidy based on chromosome analysis.

\subsubsection{Detailed analysis}

After reviewing all histograms we identified following types of peaks (each representing a cell population):

1. Diploid population was represented by a peak with a mode within the range 1.81-2.20c.

2. Peridiploid population was represented by a peak with a mode within the ranges $1.60-1.80 \mathrm{c}$ and 2.21-2.40c.

3. Tetraploid population was represented by a peak with a mode within the range $3.61-4.40 \mathrm{c}$.

4. Peritetraploid population was represented by a peak with a mode within the ranges $3.21-3.60 \mathrm{c}$ and 4.41-4.60c.

5. Aneuploid population was presented by a peak with a mode in the regions $<1.80 \mathrm{c}, 2.41-3.20 \mathrm{c}$, and $>4.60 \mathrm{c}$.

6. Multiploid histogram had a histogram with more than two peaks of tetraploid, peritetraploid or aneuploid type.

7. Cells with DNA values $>5 \mathrm{c}$. These were recorded in every histogram. We included a sample in the category of histograms with $>5 \mathrm{c}$ cells if there were at least two cells with DNA value $>5 \mathrm{c}$.

8. Some histograms were uninterpretable because the number of cells was too small for peaks to emerge. Only the presence or absence of $>5 \mathrm{c}$ cells could be recorded.

\subsubsection{Analysis according to Schröder et al. [9]}

This approach divided the samples in three categories. To this analysis, for practical reasons, we added the uninterpretable category. According to this analysis the following histogram patterns could be identified:

1. Diploid histograms had a single peak with the mode within the range $1.90-2.10 \mathrm{c}$, and $<10 \%$ of the cells in the histograms at 4c.

2. Tetraploid histograms had a peak with the mode within the range $3.90-4.10 \mathrm{c}$, and $>10 \%$ of cells of the histograms at $4 \mathrm{c}$.

3. Aneuploid histogram. This category had peak or peaks with modes at the region $<1.90 \mathrm{c}, 2.11-$ 3.90 , and $>4.10 \mathrm{c}$.

4. Uninterpretable histograms had too few cells for a peak to emerge.

\subsubsection{Condensed analysis $A$}

The condensed analysis tried to combine the categories presented under "Detailed analysis" so that a classification scale corresponding to that presented by Schröder et al. [9] was produced, but with wider ranges for diploidy and tetraploidy. So the categories were:

1. Diploid, as defined by "Detailed analysis".

2. Tetraploid, as defined by "Detailed analysis".

3. Aneuploid, including peridiploid, multiploid, and $>5$ c categories of the "Detailed analysis".

4. Uninterpretable defined as in "Detailed analysis".

\subsubsection{Condensed analysis $B$}

Again, we followed the definition of the "Detailed analysis", and the categories are those of Schröder et al. [9], but used still wider ranges for the definition of diploid or tetraploid peaks:

1. Diploid, diploid and peridiploid peaks as defined by the "Detailed analysis".

2. Tetraploid, tetraploid and peritetraploid peaks as defined by the "Detailed analysis".

3. Aneuploid, aneuploid and multiploid categories of the "Detailed analysis".

4. Uninterpretable: as defined in "Detailed analysis".

\subsubsection{Condensed analysis $C$}

This analysis was created because diploid limits in the classification of Schröder et al. were 1.90-2.10c, in the "Detailed analysis" and the condensed analysis A 1.80-2.20c, and in the condensed analysis B 1.60$2.40 \mathrm{c}$. We wanted to test only that the range $1.70-2.30 \mathrm{c}$ as the range for diploidy. So the categories in this analysis were: 
1. Diploid: peak mode within 1.70-2.30c.

2. Tetraploid: peak mode within 3.40-4.60c.

3. Aneuploid: other peaks than the above.

4. Uninterpretable categories as explained in the "Detailed analysis".

We tested the difference between two sampling rules by applying the analysis by Schröder et al. [9] and the condensed analyses A-C in two ways: first allowing the $>5 \mathrm{c}$ cells to influence the classification, and then leaving the $>5 \mathrm{c}$ cells out of the classification altogether.

\section{Results}

There was a marked difference in histograms after different types of sampling rules applied on definitely malignant FNAB samples of the prostate (Figs 1 and 2). Figure 1 shows that cells selected for measurement at the periphery of atypical cell groups could represent two peaks, one at and around the diploid region typically broader than the control cell peak, and the other, always broad at the tetraploid region. However, when cells were selected according to size, the diploid or peridiploid cells were associated with medium sized epithelial cells. The large cells were associated with a broad peak at or near the tetraploid region with the mode usually within the range of 3.5-5.0. Figure 2 also demonstrates how the DNA histograms differed with the size of the selected cells. Cells of small or moderate size showed broad peridiploid or aneuploid histograms (Fig. 2(A, B)). When larger cells were selected, also tetraploid, peritetraploid, and hypertetraploid cells were seen (Fig. 2C). If free large cells with or without detectable nucleoli were selected tetraploid and hypertetraploid cells were seen in large numbers (Fig. 2D). If the epithelial cells were selected freely between cell groups and at the periphery of cell groups, periand hyperdiploid, and hypertetraploid cells were found
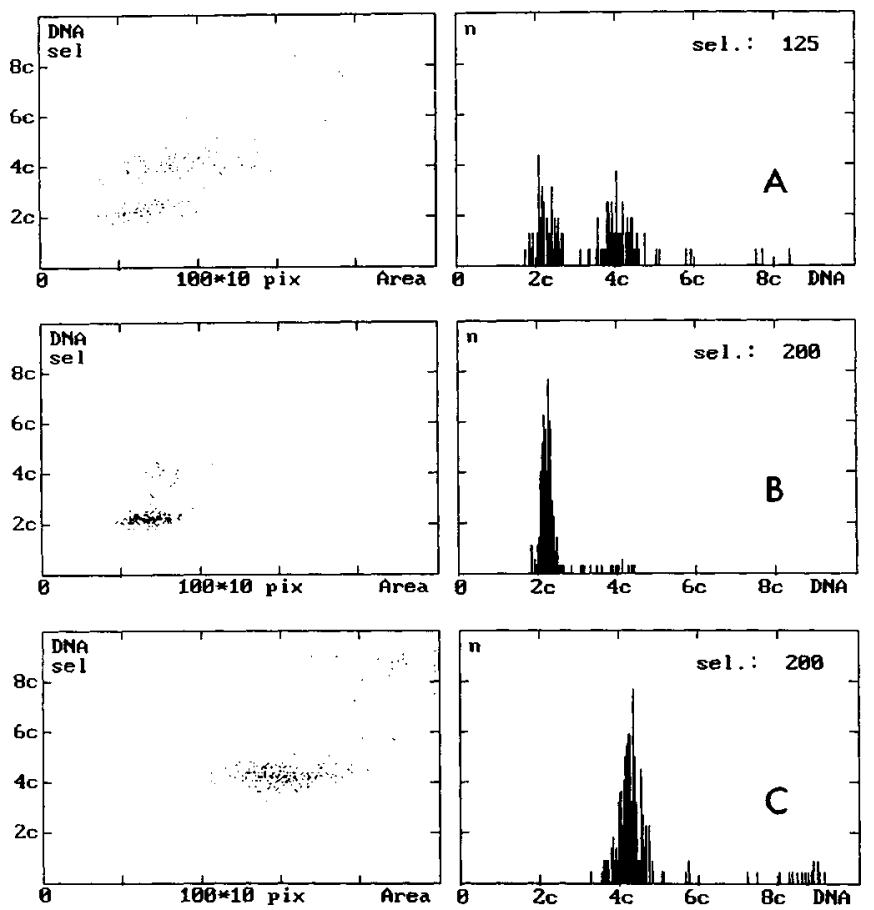

Fig. 1. Pairs of result panels of the ACAS program after measurements for DNA histograms with different sampling rules from a single sample. The measurements were made from a prostatic FNAB sample fixed in ethanol and diagnosed as definitely malignant (class 5). The left panels show a scatter-plot of DNA ploidy (vertical axis) and cell size in pixels (horizontal axis). The right panels show the DNA histograms. In all presented cases control cells were set at $2 \mathrm{c}$ and showed a thin peak $(\mathrm{CV} \leqslant 4.5 \%)$, but are not shown in the panels because of space constraints. At Fig. A nuclei were selected at the periphery of marked cell groups, and all overlapping nuclei were avoided. The histogram demonstrated broad peridiploid and peritetraploid peaks, and corresponding nuclear size classes could be demonstrated. At Fig. B medium sized cells between cell groups were selected. A peridiploid peak was produced. At Fig. C only large epithelial nuclei between cell groups were selected. Now the nuclei were much larger, and correspondingly no peridiploid nuclei are seen. But we see a broad peak representing tetraploid or hypertetraplod nuclei. The control lymphocytes defined the location of $2 \mathrm{c}$. The numbers of cells selected for analysis are shown in the panels on the right. 

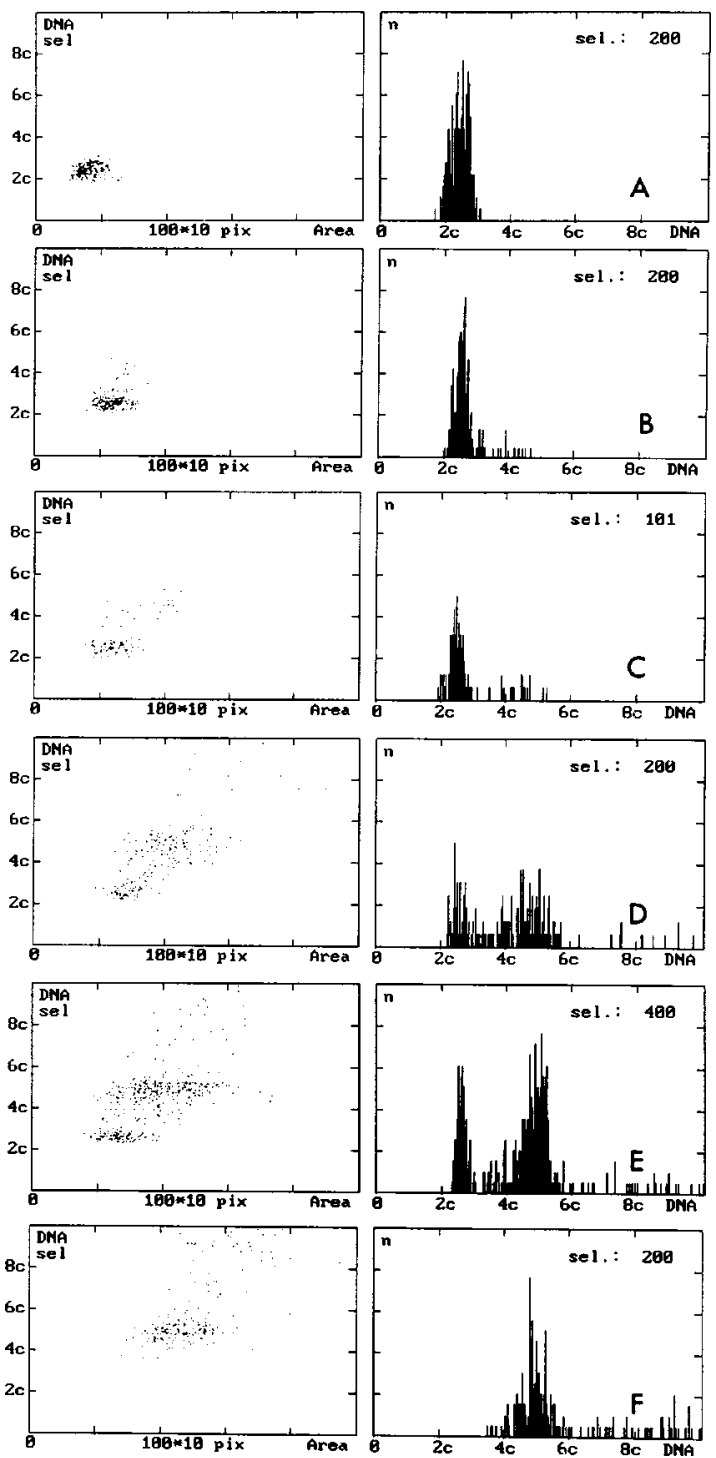

Fig. 2. DNA histograms produced from a prostatic FNAB sample diagnosed as definitely malignant (class 5). As in Fig. 1 the effect of selecting different types of nuclei on the histogram are shown. The control lymphocytes were set at 2c. In Fig. A small epithelial cells were selected between cell groups. In Fig. B medium sized nuclei were selected. In Fig. C large nuclei were selected between cell groups, cells with clearly distinguishable nucleoli were excluded. In Fig. D large nuclei with clearly distinguishable nucleoli between cell groups were selected. In Fig. E all types of epithelial nuclei between cell groups and epithelial nuclei at the periphery of cell groups (all cells without nuclear overlap) were selected. In Fig. F that large nuclei between and at the periphery of cell groups were selected. The numbers of cells selected for analysis are shown in the panels on the right.
(Fig. 2E). If only cells of large size were selected we obtained only hypertetraploid cells in the histogram (Fig. 2F).

After reviewing the results we decided to test the two sampling rules which seemed to give the most consistent results:

1. Nuclei from cell groups.

2. Free epithelial cells between cell groups.

As described in "Material and methods", 5 different classification methods were used in this comparison. The results are shown in Table 1 in which the results are described for cell groups and free cells. In addition the $>5 \mathrm{c}$ cells either were allowed or not allowed to influence the classification. However, in "Detailed analysis" $>5$ c cells were used as a classification category and this category did not change the classification based on peaks. After "Detailed analysis" diploid or peridiploid patterns could only be found in cell groups. Tetraploid or peritetraploid patterns were clearly more common among free cells. Eight out of 11 tetraploid patterns of the study were found among free cells and 6 out of 10 peritetraploid patterns. Aneuploid and multiploid patterns were not common in these cells (two in cell groups, three in free cells). $>5$ c cells were clearly more common among free cells (13 out of 18 aneuploid histograms were from among free cells). Among free cells $68.4 \%$ of samples showed $>5 \mathrm{c}$ cells, among cell groups only $23.8 \%$ of samples. The results strongly suggested that measurements on cell groups were less efficient in detecting abnormality than the measurements done on free cells.

The other methods of interpretation revealed a similar pattern. The classification of Schröder et al. [9] well revealed the cell group/free cell difference in diploid histograms but did not show as striking differences in the tetraploid or aneuploid histograms. The classifications "Condensed A-C" clearly showed the difference in diploid pattern between cell groups and free cells. These three methods also showed a marked difference in the number of aneuploid histograms between analyses with or without $>5 \mathrm{c}$ cells. In the "Condensed B" classification the change was also striking.

If tetraploid and aneuploid patterns were considered suggestive of cancer, then the 4 histogram classifications (Schröder et al. [9], "Condensed A-C") revealed more suspicious histograms among free cells than among cell groups, especially when $>5 \mathrm{c}$ cells were considered for analysis. This is shown in Table 2. Clearly, among free cells, no diploid patterns were found. But cell group-based sampling often showed 
Table 1

The distribution of histograms in different histogram type categories according to different interpretation methods (Detailed analysis, Method of Schröder et al. [9], Condensed classifications A-C), and according to whether $>5 \mathrm{c}$ cells present in the sample are or are not considered as definite signs of aneuploidy. The material was 21 definitely malignant FNAB samples, sampled either from cell groups or free cells between cell groups

\begin{tabular}{|c|c|c|c|c|}
\hline \multirow{2}{*}{$\begin{array}{l}\text { Interpretation methods } \\
\text { and histogram types }\end{array}$} & \multicolumn{2}{|c|}{ Cell groups } & \multicolumn{2}{|c|}{ Free cells } \\
\hline & $\begin{array}{l}\text { Peak-based } \\
\text { analysis only }\end{array}$ & $\begin{array}{l}>5 \mathrm{c} \text { cells } \\
\text { considered }\end{array}$ & $\begin{array}{l}\text { Peak-based } \\
\text { analysis only }\end{array}$ & $\begin{array}{l}>5 \mathrm{c} \text { cells } \\
\text { considered }\end{array}$ \\
\hline \multicolumn{5}{|l|}{ Detailed analysis } \\
\hline Diploid & 7 & & 0 & \\
\hline Peridiploid & 6 & & 0 & \\
\hline Tetraploid & 3 & & 8 & \\
\hline Peritetraploid & 4 & & 6 & \\
\hline Aneuploid & 2 & & 1 & \\
\hline Multiploid & 0 & & 2 & \\
\hline Uninterpretable & 0 & & 2 & \\
\hline$>5 c^{*}$ & & 5 & & 13 \\
\hline \multicolumn{5}{|l|}{ Schröder et al. [9] } \\
\hline Diploid & 6 & 6 & 0 & 0 \\
\hline Tetraploid & 2 & 1 & 3 & 2 \\
\hline Aneuploid & 13 & 14 & 15 & 17 \\
\hline Uninterpretable & 0 & 0 & 3 & 2 \\
\hline \multicolumn{5}{|l|}{ Condensed A } \\
\hline Diploid & 7 & 7 & 0 & 0 \\
\hline Tetraploid & 3 & 2 & 8 & 3 \\
\hline Aneuploid & 11 & 12 & 10 & 16 \\
\hline Uninterpretable & 0 & 0 & 3 & 2 \\
\hline \multicolumn{5}{|l|}{ Condensed B } \\
\hline Diploid & 13 & 13 & 0 & 0 \\
\hline Tetraploid & 6 & 4 & 15 & 3 \\
\hline Aneuploid & 2 & 4 & 3 & 16 \\
\hline Uninterpretable & 0 & 0 & 3 & 2 \\
\hline \multicolumn{5}{|l|}{ Condensed C } \\
\hline Diploid & 8 & 8 & 0 & 0 \\
\hline Tetraploid & 5 & 4 & 11 & 4 \\
\hline Aneuploid & 8 & 9 & 7 & 15 \\
\hline Uninterpretable & 0 & 0 & 3 & 2 \\
\hline
\end{tabular}

$*>5$ c category may overlap with other categories.

diploid patterns. As seen in Table 1, histograms from free cells also showed $>5 \mathrm{c}$ cells more often than cell groups.

\section{Discussion}

Our results clearly show that the sampling method affects the appearance of the histogram in FNABies of the prostate. Because DNA histograms were generally more abnormal after the second sampling rule it seems that the free cells should be favoured when producing
DNA histograms of cancer samples. But do we lose biological information if we do not measure the cell groups? This question is relevant, because the cytological diagnosis of malignancy is often based on evaluation of cells within cell groups.

Because after sampling the free cells no diploid histograms were produced we can state that in respect to searching for tetraploidy or aneuploidy, the free cells are a richer pool of information than cell groups (Tables 1 and 2). Our study also showed that the value of free cells in exposing the non-diploid cell pattern was independent of the classification method used for the 
Table 2

Diploid histograms and histograms of non-diploid character, including peridiploid, tetraploid, peritetraploid, aneuploid and multiploid patterns after two sampling methods, and two different ways of interpretation of the $>5 \mathrm{c}$ cells

\begin{tabular}{|c|c|c|c|c|}
\hline \multirow{2}{*}{$\begin{array}{l}\text { Interpretation methods } \\
\text { and histogram types }\end{array}$} & \multicolumn{2}{|c|}{$>5 \mathrm{c}$ cells neglected } & \multicolumn{2}{|c|}{$>5 \mathrm{c}$ cells as sign of aneuploidy } \\
\hline & Cell groups & Free cells & Cell groups & Free cells \\
\hline \multicolumn{5}{|l|}{ Schröder et al. [9] } \\
\hline Diploid & 6 & 0 & 6 & 0 \\
\hline Non-diploid & 15 & 18 & 15 & 19 \\
\hline \multicolumn{5}{|l|}{ Condensed A } \\
\hline Diploid & 7 & 0 & 7 & 0 \\
\hline Non-diploid & 14 & 18 & 14 & 19 \\
\hline \multicolumn{5}{|l|}{ Condensed B } \\
\hline Diploid & 13 & 0 & 13 & 0 \\
\hline Non-diploid & 8 & 18 & 8 & 19 \\
\hline \multicolumn{5}{|l|}{ Condensed C } \\
\hline Diploid & 8 & 0 & 8 & 0 \\
\hline Non-diploid & 13 & 18 & 13 & 19 \\
\hline
\end{tabular}

histograms. Because non-diploid patterns were seen in all measurements based on free cells, this sampling approach did not seem to produce false negatives. If this is a general rule it is obvious that sampling of free cells is in all cases more efficient in detecting non-diploid cell populations than the sampling approach based on cell groups. Under these circumstances one should recommend the sampling based on free cells. One can even expect that cells from the cell groups sampled in association with the free cells might be able to hide the presence of more abnormal cells, especially when the number of measurable cells in cell groups is large.

What is the nature of the free cells in these samples? We feel that free cells - with respect to malignant disease - are more advanced cells than the cells which still are coherent and form cell groups. Decreased coherence in breast FNAB is also suggestive of carcinoma [12]. In prostate cancer the presence of free cells may reflect advanced disease, because the infilterative pattern with single cells (included in Gleason score 5) probably is present in samples showing free cells in FNAB.

Our findings no doubt may have therapeutic consequences. However, combining the described features with the follow-up of the patients will be necessary before the clinical relevance of findings can be proven. It is clear, however, that if non-diploidy is considered as a reliable sign of treatable malignancy, free cellsbased sampling will find a higher number of patients for therapy than cell group-based analysis. We are now progressing towards studies, which will include patient follow up data which has not been available in this study. However, the method as presented may already, at this stage of knowledge, be of diagnostic and therapeutic significance. We can imagine a situation in which a sample is classified as suspicious after the FNAB. In such a case, further information is available after image cytometric DNA ploidy analysis. If aneuploid or tetraploid histograms are detected one can expect that the sample presents prostate cancer. But at this stage of knowledge direct conclusions in respect to type of recommendable therapy can not be drawn from the analysis.

\section{Conclusion}

We can state that when studying prostate FNABies for DNA profile, one should use the free cells of the sample to detect abnormality at highest efficiency.

\section{Acknowledgements}

We thank Mrs Sinikka Kollanus for help in preparing the samples for analysis. The study was supported by grants from the Finnish Cancer Society, Turku University Foundation, Paivikki and Sakari Sohlberg Foundation, and Turku University Hospital.

\section{References}

[1] P. Chieco, A. Jonker, C. Melchiorri, G. Vanni and C.J. van Noorden, A user's guide for avoiding error in absorbance image cytometry, Journal of Histochemistry 26 (1994), 1-19. 
[2] D.A. Diamond, S.F. Berry, H.J. Jewett, J.C. Eggleston and D.S. Coffey, A new method to assess metastatic potential of human prostate cancer: relative nuclear roundness, Journal of Urology 128 (1982), 729-734.

[3] O.S. Frankfurt, J.L. Chin and L.S. Englander, Relationship between DNA ploidy, glandular differentiation and tumor spread in human prostate cancer, Cancer Research 45 (1985), 1418 1423 .

[4] J. Gaub, G. Auer and A. Zetterberg, Quantitive cytological aspects of a combined Feulgen naphthol yellow S staining procedure for the simultaneous determinatins of nuclear and cytoplasmic protein and DNA in mammalian cells, Experimental Cell Research 92 (1975), 323-332.

[5] D.J. Goldstein, Aspects of scanning microdensitometry. I. Stray light (glare), Journal of Microscopy 92 (1970), 1-16.

[6] O. Native, H.Z. Winkler, Y. Raz, T.M. Therneau, G.M. Farrow, R.P. Myers, H. Zincke and M.M. Lieber, Stage C prostate adenocarcinoma: flow cytometric nuclear DNA ploidy analysis, Mayo Clinic Proceedings 64 (1989), 911-919.

[7] J.M. Peters, B.J. Miles, J.J. Kubus and J.D. Crissman, Prognostic significance of the nuclear DNA content in localized prostatic adenocarcinoma, Analytical and Quantitative Cytology and Histology 12 (1990), 359-364.

[8] C.N. Robertson and D.F. Paulson, DNA in radical prostatectomy specimens: prognostic value of tumor ploidy, Acta Oncologica 30 (1991), 205-207.

[9] F. Schröder, B. Tribukait, A. Bocking, R. DeVere White, L. Koss, M. Lieber, B. Stenkvist and A. Zetterberg, Clinical utility of cellular DNA measurement in prostate carcinoma. Di- agnostic and prognostic parameters in localized prostate cancer. Proceedings of a symposium in Stockholm, Sweden, 1213 May 1993, L. Anderson, ed., Scandinavian Journal of Urology and Nephrology Supplementum 162 (1994), 51-64.

[10] J. Shaeffer, J.A. Tegeler, D.A. Kuban, C.B. Philput and A.M. EL-Mahdi, Nuclear roundness factor and local failure from definitive radiation therapy for prostate carcinoma, International Journal of Radiation Oncology, Biology, Physics $\mathbf{2 4}$ (1992), 431-434.

[11] I.F. Silverman, Breast, in: Comprehensive Cytopathology, M. Bibbo, ed., W.B. Saunders Company, Harcourt Brace Fovanovich Inc., Philadelphia, IL, 1991, pp. 703-770.

[12] R.A. Stephenson, B.C. James and U. Gay, Flow cytometry of prostate cancer: relationship of DNA content to survival, Cancer Research 47 (1987), 2504-2509.

[13] B. Tribukait, DNA flow cytometry in carcinoma of the prostate for diagnosis, prognosis and study of tumor biology, Acta Oncologica 30 (1991), 187-192.

[14] L.A. Talve, Y.U. Collan and T.O. Ekfors, Primary malignant melanoma of the skin. Relationships of nuclear DNA content, nuclear morphometric variables, Clark level and tumor thickness, Analytical and Quantitative Cytology and Histology 19 (1997), 62-74.

[15] N. Wang, T. Heiden and B. Tribukait, Fluorescence image cytometry for measurement of nuclear DNA content in surgical pathology, Cytometry 22 (1995), 323-329. 


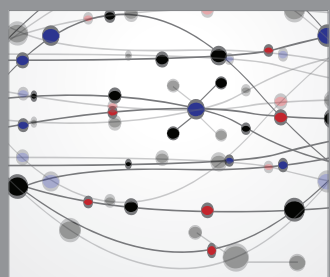

The Scientific World Journal
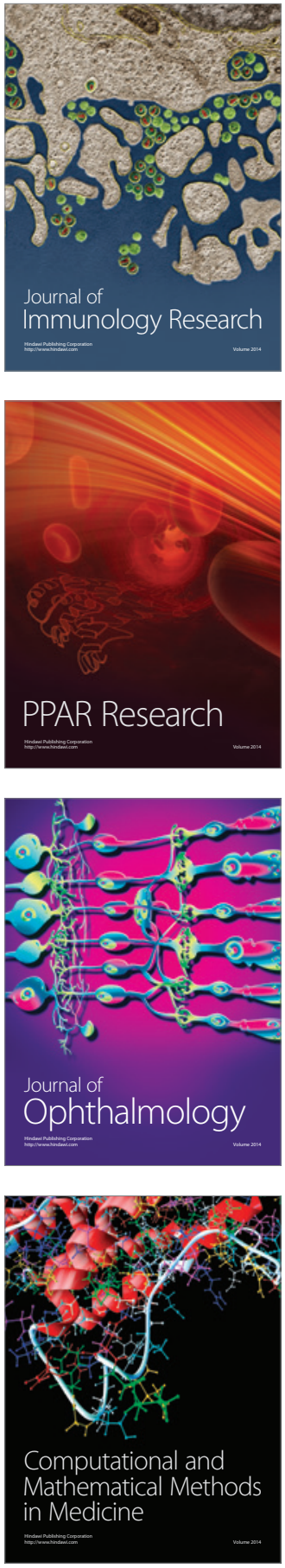

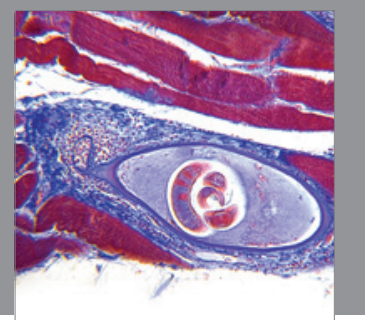

Gastroenterology

Research and Practice
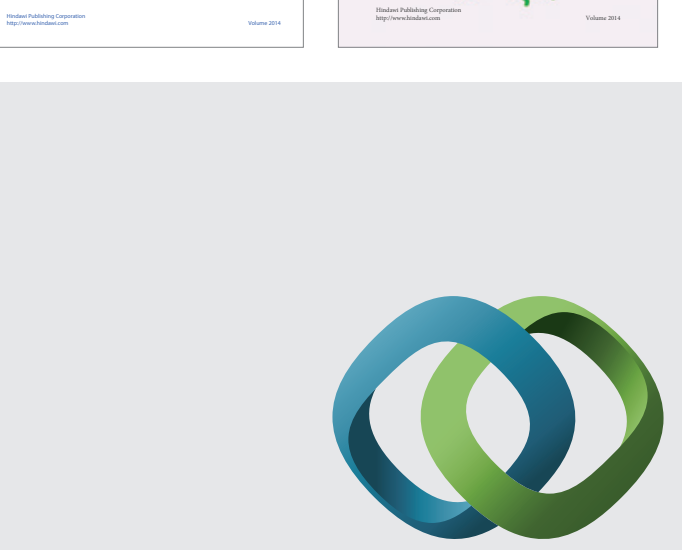

\section{Hindawi}

Submit your manuscripts at

http://www.hindawi.com
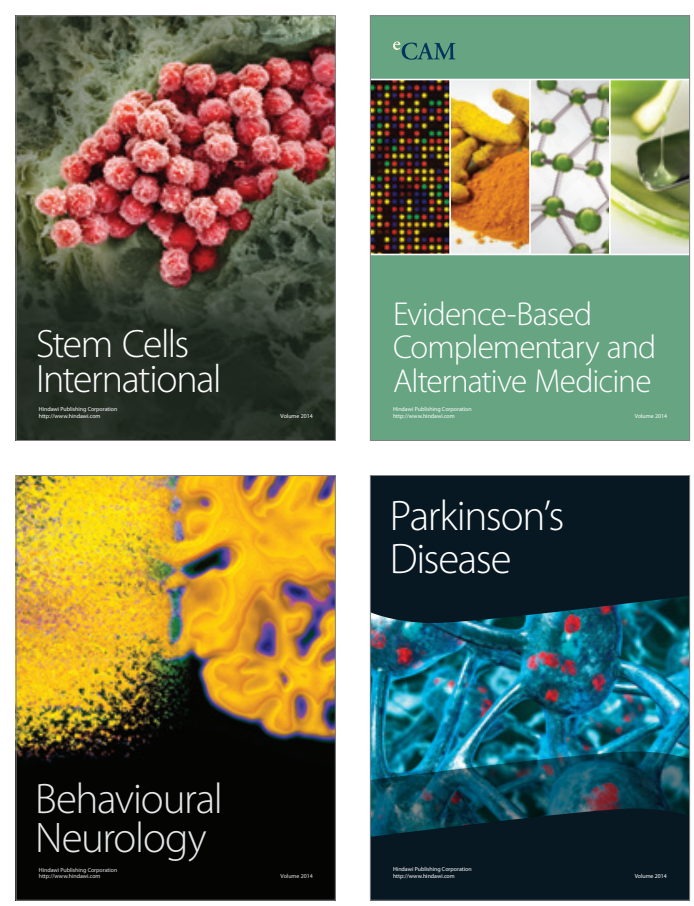

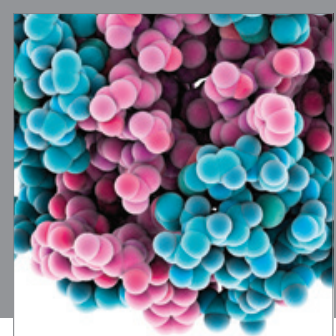

Journal of
Diabetes Research

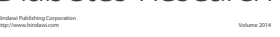

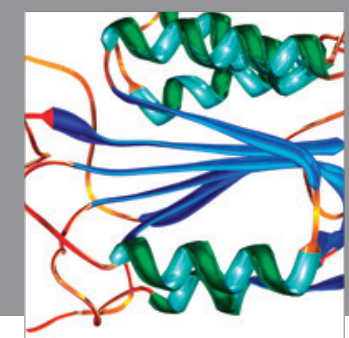

Disease Markers
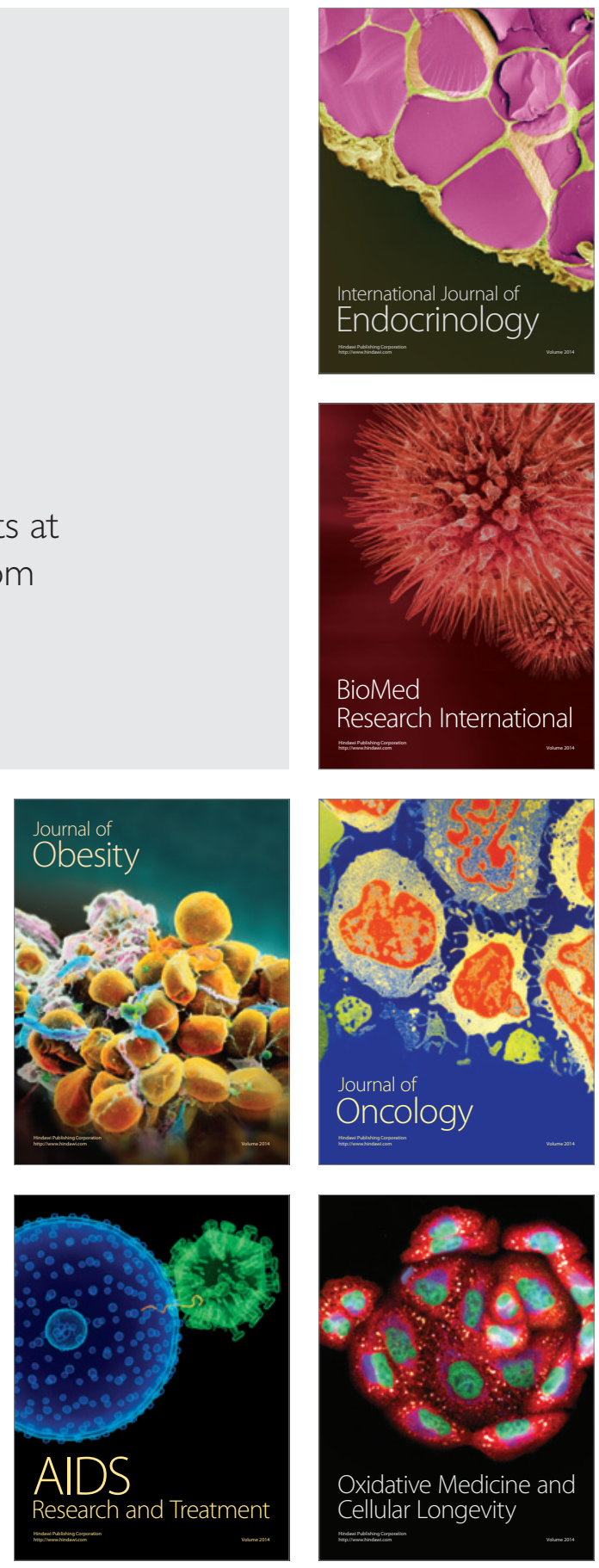